\title{
Pemberian Informasi dan Kelengkapan Pengisian Informed Consent Pada Pasien Sectio Caesarea Di RS PKU Muhammadiyah Gamping Yogyakarta
}

\author{
Information Disclosure and the Completeness of Informed Consent for \\ Caesarean Section Patients at PKU Muhammadiyah Gamping Hospital \\ Yogyakarta
}

\author{
Ratna Prahesti1) \\ Eva Putriningrum²)
}

\author{
1,2) Jurusan Rekam Medis dan Informasi Kesehatan \\ Universitas Jenderal Achmad Yani Yogyakarta \\ Jl. Brawijaya Ringroad Barat Ambarketawang Gamping Sleman Yogyakarta \\ E-mail: ratna.curve@gmail.com, evaputriningrum@gmail.com
}

\begin{abstract}
Hospital in a form of public facility provides comprehensive health care services. As a part of the healthcare system, patient safety intended to prevent and reduce risks, errors and harms that occur to patients. During the provision of healthcare services, patients and their families are subject to receive direct and detailed information regarding purposed medical procedure. The information includes diagnosis, expected outcomes, alternative intervention, risk, complications, prognosis and estimated cost. This study intended to describe the process of informational disclosure toward patients and assess the completeness of informed consent among caesarean section patients. This is a descriptive qualitative and quantitativ study involving 57 patients and 4 informant admitted to PKU Muhammadiyah Gamping Hospital during first quarter of 2020. Participants were recruited through accidental sampling method. Univariate statistical analysis was performed to explore the study findings. This research discover that information disclosure was performed prior to medical intervention in a concise and understandable language for the patients. Despite the disclosure was performed in a simplified language, study reported incomplete informed consent dominated from authentication section. Among 57 informed consent, $49,13 \%$ were incompletely filled in.
\end{abstract}

Keywords: information disclosure, informed consent, caesarean section patients.

\begin{abstract}
Abstrak
Rumah sakit merupakan fasilitas pelayanan kesehatan yang menyelengarakan pelayanan kesehatan secara paripurna. Dalam upaya perlindungan keselamatan pasien, pasien maupun keluarga wajib mendapatkan penjelasan informasi secara langsung dan jelas mengenai tindakan kedokteran yang akan dilakukan kepada pasien baik diminta maupun tidak diminta mengenai informasi diagnosis, tujuan, alternatif tindakan, risiko, komplikasi yang mungkin terjadi, prognosis mengenai tindakan yang dilakukan, serta perkiraan biaya pengobatan yang disebut informed consent. Tujuan penelitian adalah mendeskripsikan pelaksanaan pemberian informasi pasien dan menganalisa presentase kelengkapan informed consent khususnya pada pasien bedah sectio caesaria (SC). Penelitian ini menggunakan metode deskriptif kualitatif dan kuantitatif. Sampel penelitian adalah pasien bedah sectio caesarea pada triwulan pertama tahun 2020 sebanyak 57 pasien, dan 4 informan dengan teknik pengambilan accidental sampling. Analisis data menggunakan analisis statistik univariat. Hasil Penelitian yaitu penjelasan mengenai informed consent disampaikan dengan bahasa yang jelas dan mudah dipahami pasien dan pemberian informasi dilakkukan sebelum dilakukannya tindakan kedokteran. Meskipun
\end{abstract}


sudah dijelaskan dengan bahasa yang mudah dipahami namun masih ditemukan formulir informed consent yang tidak lengkap terutama pada bagian autentifikasi. Ditemukan sebanyak $49,13 \%$ formulir informed consent yang tidak terisi lengkap dari 57 formulir informed consent.

Kata Kunci: pemberian informasi; pasien bedah sectio caesaria; informed consent.

\section{Pendahuluan}

Berdasarkan Undang-undang Republik Indonesia nomor 29 tahun 2009, Rumah Sakit merupakan salah satu fasilitas pelayanan kesehatan yang menyelenggarakan pelayanan kesehatan perorangan secara paripurna terdiri dari pelayanan rawat inap, rawat jalan, dan gawat darurat. Rumah Sakit bertujuan memberikan pelayanan terbaik dan perlindungan pada keselamatan pasien, masyarakat, lingkungan rumah sakit dan tenaga kesehatan dengan meningkatkan mutu dan mempertahankan standar pelayanan rumah sakit (Presiden RI, 2009).

Dalam upaya perlindungi keselamatan pasien, pasien maupun keluarga terdekat wajib mendapatkan penjelasan informasi secara langsung, baik diminta maupun tidak diminta, mengenai informasi diagnosis dan tindakan medis, tujuan tindakan medis, alternatif tindakan, risiko dan komplikasi yang mungkin terjadi, prognosis mengenai tindakan yang dilakukan, serta perkiraan biaya pengobatan. Pasien maupun keluarga terdekat berhak memberikan persetujuan atau menolak tindakan yang akan dilakukan oleh tenaga kesehatan terhadap sakit yang diderita pasien maupun keluarganya. Adanya informed consent sebelum tindakan pembedahan akan memberikan kepuasan terhadap keputusannya dalam tindakan pembedahan (Hallock et al., 2017).

Informed Consent adalah persetujuan yang diberikan oleh pasien atau walinya yang berhak kepada dokter untuk melakukan suatu tindakan medis terhadap pasien sesudah memperoleh informasi lengkap dan yang dipahaminya mengenai tindakan itu (Octaria \& Trisna, 2016).
Berdasarkan Peraturan Menteri Kesehatan Nomor 290 tahun 2008 tentang Informed consent adalah salah satu dasar yang sangat penting dalam pertimbangan para dokter untuk mengambil tindakan medis guna menyelamatkan nyawa pasien. Informed consent yang komprehensif menghormati otonomi pasien, trasnparan, dan adanya pengambilan keputusan (Mavroudis \& Thomas Cook, 2020).

Informed consent harus diisi lengkap dan jelas oleh pasien atau keluarga. Kelengkapan Informed Consent sangat penting bagi pelaksana pelayanan kesehatan, sebab dari Informed Consent lahir perjanjian atau kesepakatan kesehatan, adanya perjanjian kesehatan merupakan faktor penentu dan menumbuhkan rasa aman dan nyaman bagi seorang dokter atau tenaga kesehatan untuk menjalankan tugasnya sebagai pemberi pelayanan kesehatan. Apabila pengisian Informed Consent tidak lengkap hal ini akan berdampak pada keselamatan pemberi pelayanan kesehatan terutama bila kemungkinan terjadi perselisihan antara pasien dengan dokter atau rumah sakit dikemudian hari. Apabila dari formulir tersebut tidak diisi dengan lengkap, maka akan mengakibatkan informasi yang ada di dalam rekam medis akan menjadi tidak tepat, tidak akurat dan tidak dapat digunakan sebagai alat untuk melepaskan diri dari tuntutan apabila terjadi sesuatu yang merugikan pasien (Ulfa, 2018).

Seksio sesarea tidak dapat dilakukan jika belum terdapat persetujuan tindakan (informed consent) dari pihak keluarga atau pasien. Dari segi hukum, Informed Consent dalam pelayanan kesehatan adalah hal yang harus dilakukan, sehingga 
implementasi kesepakatan tindakan medis perlu diperhatikan dalam penyelenggaraannya, dan adanya perlindungan hukum baik bagi pasien maupun dokter (Busro, 2018).

Berdasarkan permasalahan tersebut peneliti tertarik untuk melakukan penelitian dengan judul "Pelaksanaan Pemberian Informasi dan Kelengkapan Informed Consent Pada Pasien Bedah Sectio Caesarea Di RS PKU Muhammadiyah Gamping Yogyakarta".

\section{Metode}

Penelitian ini menggunakan metode penelitian deskriptif dengan pendekatan kualitatif dan kuantitatif. Penelitian deskriptif pada penelitian ini bertujuan menguraikan tentang pemberian informasi dan kelengkapan pengisian informed consent pada pasien Sectio Caesarea di RS PKU Muhammadiyah Gamping Yogyakarta. Penelitian ini menggunakan accidental sampling sejumlah 57 berkas rekam medis, pada triwulan pertama tahun 2020 dan 4 petugas yang memenuhi kriteria. Variabel dalam penelitian ini adalah pelaksaan pemberian informasi dan kelengkapan pengisian Informed Consent. Instrumen yang digunakan adalah lembar observasi ceklist dan panduan wawancara.

\section{Hasil dan Pembahasan}

Hasil wawancara kepada petugas tentang pelaksanaan pemberian informasi terkait informed consent yaitu pada pasien sudah diberikan penjelasan informed consent sebelum tindakan SC yang dilakukan di pendaftaran rawat inap, IGD, dan poli ketika dokter merencanakan operasi. Dalam praktiknya dokter berkewajiban memberikan informasi dan mendapatkan persetujuan dari pasien sebelum dilakukan tindakan medis (Sprumont, 2017). Hal ini sejalan dengan hasil penelitian yang dilakukan $\mathrm{H}$. Octaria tahun 2016 di RSUD Bangkinang dengan hasil bahwa pelaksanaan pemberian informasi sudah ada, dimulai dari ruang rawat inap dokter memberikan informasi sampai dengan pasien sebelum melakukan tindakan medik (Octaria \& Trisna, 2016). Petugas memberikan penjelasan dengan bahasa yang jelas dan mudah dipahami oleh pasien atau keluarga pasien sesuai ketentuan prosedur mengenai pengisian formulir informed consent. Informed consent yang dilakukan di PKU Muhammadiyah Gamping tidak hanya oleh Dokter tetapi juga perawat. Tanggung jawab utama dalam tindakan medis ada pada dokter, tetapi perawat juga berperan dalam memberikan dukungan, ataupun saksi dalam pemberian Informed consent (Susilo et al., 2013). Pemberian informed consent pada pasien pre operasi bertujuan untuk menurunkan kecemasan dan meningkatkan pengetahuan, hasil studi menunjukkan bahwa pemberian informed consent berpengaruh terhadap kecemasan sebesar 20.90 poin lebih baik dibanding tanpa informed consent (Prihyanto, 2012).

Meskipun petugas sudah meyampaikan dengan bahasa yang mudah dipahami mengenai penjelasan informasi tindakan medis yang akan dilakukan, namun pelaksanaannya masih belum berjalan dengan baik sesuai dengan ketentuan yang berlaku. Hal ini dapat dilihat dari masih adanya sebagian formulir informed consent yang tidak terisi lengkap. 
Hasil penelitian mengenai kelengkapan pengisian formulir informed consent Tindakan SC adalah sebagai berikut:

Tabel 1. Prosentase Kelengkapan Pengisian Informed Consent pasien SC di RS PKU Muhammadiyah Gamping

\begin{tabular}{|c|c|c|c|c|}
\hline \multirow[t]{3}{*}{ No } & \multirow{3}{*}{$\begin{array}{l}\text { Bu- } \\
\text { lan }\end{array}$} & \multirow{3}{*}{$\begin{array}{l}\text { Jumlah } \\
\text { Formulir } \\
\text { IC }\end{array}$} & \multicolumn{2}{|c|}{ Prosentase (\%) } \\
\hline & & & Leng- & Tidak \\
\hline & & & Kap & $\begin{array}{l}\text { Leng- } \\
\text { kap }\end{array}$ \\
\hline 1. & Mei & 10 & $4(40 \%)$ & $6(60 \%)$ \\
\hline \multirow[t]{2}{*}{2.} & Juni & 22 & $9(40,90$ & 13 \\
\hline & & & $\%)$ & $(59,10 \%)$ \\
\hline 3. & Juli & 10 & $5(50 \%)$ & $5(50 \%)$ \\
\hline \multirow[t]{2}{*}{4.} & Agus & 15 & $11(73,33$ & 4 \\
\hline & tus & & $\%)$ & $(26,66 \%)$ \\
\hline \multirow{2}{*}{\multicolumn{2}{|c|}{$\begin{array}{c}\text { Total } \\
\text { Formulir IC }\end{array}$}} & 57 & $29(50,87$ & 28 \\
\hline & & & $\%)$ & $(49,13 \%)$ \\
\hline
\end{tabular}

Sumber: Hasil Observasi Penelitian Bulan September 2020

Dari Tabel 1 di atas dapat diketahui prosentase kelengkapan pengisian formulir informed consent pasien section caesarea pada bulan Mei- Agustus 2020. Masih ditemukan formulir informed consent yang tidak terisi lengkap sebanyak $28(49,13 \%)$ formulir informed consent dan 29 (50,87\%) formulir informed consent yang terisi lengkap. Hasil penelitian ini sama dengan hasil penelitian kelengkapan pengisian informed consent tindakan bedah di RS Pertamina Bintang Amin yaitu masih adanya informed consent yang belum lengkap, sebanyak 23 (23\%) informed consent (Wulandari et al., 2019).

Tabel 2. Identitas Penerima Informasi

\begin{tabular}{llcccc}
\hline No & Data & \multicolumn{3}{c}{ Kelengkapan } \\
& & \multicolumn{2}{c}{ Ya } & \multicolumn{2}{c}{ Tidak } \\
& & $\mathrm{N}$ & $\%$ & $\mathrm{~N}$ & $\%$ \\
\hline 1. & Nama & 54 & $94,74 \%$ & 3 & $5,26 \%$ \\
2. & Tanggal & 55 & $96,50 \%$ & 2 & $3,50 \%$ \\
& lahir & & & & \\
3. & No. RM & 55 & $96,50 \%$ & 2 & $3,50 \%$ \\
\hline
\end{tabular}

Sumber data: Hasil observasi penelitian bulan September 2020
Tabel 3. Kelengkapan Pengisian Identitas Keluarga Pasien (Penerima Informasi)

\begin{tabular}{|c|c|c|c|c|c|}
\hline \multirow[t]{3}{*}{ No } & \multirow[t]{3}{*}{ Data } & \multicolumn{4}{|c|}{ Kelengkapan } \\
\hline & & \multicolumn{2}{|r|}{$\mathrm{Ya}$} & \multicolumn{2}{|c|}{ Tidak } \\
\hline & & $\mathrm{N}$ & $\%$ & $\mathrm{~N}$ & $\%$ \\
\hline 1. & $\begin{array}{l}\text { Tanggal } \\
\text { Persetujuan }\end{array}$ & 53 & $92,99 \%$ & 4 & $7,01 \%$ \\
\hline 2. & Waktu & 53 & $92,99 \%$ & 4 & $7,01 \%$ \\
\hline 3. & Nama & 47 & $82,46 \%$ & 10 & $17,54 \%$ \\
\hline
\end{tabular}

Tabel 4. Kelengkapan Pengisian Identitas Pemberi Informasi

\begin{tabular}{cccccc}
\hline No & Data & \multicolumn{3}{c}{ Kelengkapan } \\
\cline { 2 - 5 } & & \multicolumn{3}{c}{ Ya } & \multicolumn{2}{c}{ Tidak } \\
& & $\mathrm{N}$ & $\%$ & $\mathrm{~N}$ & $\%$ \\
\hline 1. & $\begin{array}{l}\text { Nama } \\
\text { Dokter }\end{array}$ & 50 & $87,72 \%$ & 7 & $12,28 \%$
\end{tabular}

Sumber data: Hasil observasi penelitian bulan September 2020

Tabel 5. Kelengkapan Pengisian Pelaporan Penting

\begin{tabular}{|c|c|c|c|c|c|}
\hline \multirow[t]{3}{*}{ No } & \multirow[t]{3}{*}{ Data } & \multicolumn{4}{|c|}{ Kelengkapan } \\
\hline & & \multicolumn{2}{|r|}{$\mathrm{Ya}$} & \multicolumn{2}{|c|}{ Tidak } \\
\hline & & $\mathrm{N}$ & $\%$ & $\mathrm{~N}$ & $\%$ \\
\hline 1. & $\begin{array}{l}\text { Diagnosis } \\
\text { kerja }\end{array}$ & 54 & $94,74 \%$ & 3 & $5,26 \%$ \\
\hline 2. & $\begin{array}{l}\text { Dasar } \\
\text { diagnosis }\end{array}$ & 55 & $96,50 \%$ & 2 & $3,50 \%$ \\
\hline 3. & $\begin{array}{l}\text { Tindakan } \\
\text { kedokteran }\end{array}$ & 55 & $96,50 \%$ & 2 & $3,50 \%$ \\
\hline 4. & $\begin{array}{l}\text { Tatacara } \\
\text { tindakan }\end{array}$ & 54 & $96,50 \%$ & 3 & $3,50 \%$ \\
\hline 5. & $\begin{array}{l}\text { Indikasi } \\
\text { dan tujuan }\end{array}$ & 55 & $96,50 \%$ & 2 & $3,50 \%$ \\
\hline 6. & Risiko & 55 & $96,50 \%$ & 2 & $3,50 \%$ \\
\hline 7. & Komplikasi & 55 & $96,50 \%$ & 2 & $3,50 \%$ \\
\hline 8. & Prognosis & 55 & $96,50 \%$ & 2 & $3,50 \%$ \\
\hline 9. & $\begin{array}{l}\text { Alternatif } \\
\text { tindakan }\end{array}$ & 48 & $84,22 \%$ & 9 & $15,78 \%$ \\
\hline
\end{tabular}

Sumber data: Hasil observasi penelitian bulan September 2020 
Tabel 6. Kelengkapan Pengisian Autentifikasi

\begin{tabular}{clllll}
\hline No & Data & \multicolumn{3}{c}{ Kelengkapan } \\
& & $\mathrm{N}$ & $\%$ & $\mathrm{~N}$ & \multicolumn{2}{c}{ Tidak } \\
\hline 1. & $\begin{array}{l}\text { Nama } \\
\text { dokter }\end{array}$ & 50 & $87,7 \%$ & 7 & $12,28 \%$ \\
2. & $\begin{array}{l}\text { Tanda } \\
\text { tangan }\end{array}$ & 55 & $96,50 \%$ & 2 & $3,50 \%$ \\
3. & $\begin{array}{l}\text { Nama } \\
\text { keluarga } \\
\text { /pasien }\end{array}$ & 47 & $82,46 \%$ & 10 & $17,54 \%$ \\
4. & $\begin{array}{l}\text { Tanda } \\
\text { tangan }\end{array}$ & 52 & $91,23 \%$ & 5 & $8,77 \%$ \\
\hline
\end{tabular}

Sumber data: Hasil observasi penelitian bulan September 2020

Pada Tabel 2 identitas penerima informasi paling banyak adalah nama yang tidak lengkap sebanyak 3 informed consent $(5,26 \%)$. Pada Tabel 3 ketidaklengkapan pengisian identitas keluarga pasien (penerima informasi) paling banyak adalah nama penerima informasi sebanyak 10 informed consent $(17,54 \%)$. Pada Tabel 4, sebanyak 7 (12,28\%) informed consent tidak lengkap nama pemberi informasi. Hal ini sesuai dengan hasil penelitian analisis informed consent di RSUD Kota Semarang bahwa dokter mengetahui fungsi dan tujuan informed consent tetapi kurang mengetahui konsekwensi hukum informed consent, serta prosedur, kebijakan, pengawasan, dan sanksi Rumah Sakit belum menjamin kepatuhan dalam mengimplementasikan informed consent (Jati et al., 2016). Tabel 5 mengenai kelengkapan pengisian laporan penting paling banyak yang tidak lengkap adalah data alternatif tindakan sebanyak 9 $(15,78 \%)$ informed consent. Tabel 6 pada pengisian autentifikasi paling banyak yang tidak lengkap pada data namakeluarga/pasien sebanyak $10(17,54 \%)$ informed consent.

Pemberian informed consent merupakan penghubung antara dokter dengan pasien yang merupakan komunikasi dalam menentukan pengobatan dan terapi terbaik kepada pasien, serta harus dijelaskan dengan lengkap dan jelas kepada pasien atau keluarga pasien. Selain itu, penjelasan dan proses pencatatan dan permintaan tanda tangan menjadi persetujuan yang diperlukan sebagai syarat pelaksanaan informed consent yang baik sesuai aspek hukum.

Sectio caesarea di Rumah Sakit PKU Muhammadiyah Gamping, dilakukan pada pasien sesuai dengan kondisi yang telah ditentukan oleh dokter penanggung jawab serta kondisi pasien dalam keadaan darurat. Penjelasan mengenai informed consent disampaikan kepada pasien dengan menggunakan bahasa yang jelas dan mudah dipahami pasien atau keluarga, namun masih ditemukan beberapa formulir informed consent yang tidak lengkap terutama pada autentifikasi bagian tanda tangan dan nama penerima informasi, hal ini disebabkan karena kurangnya pemahaman pasien akan pentingnya informed consent, selain itu dikarenakan juga kesibukan dokter yang menyebabkan terkadang dokter tidak melengkapi formulir informed consent yang disampaikan. Hal serupa juga terjadi didalam implementasi pengisian formulir informed consent di RSUD dr Soekardjo Tasikmalaya yaitu penghambat kelengkapan pengisian formulir informed consent diantaranya keterbatasan waktu, kurangnya sumber daya manusia, dan kurangnya sosialisasi (Wahyuni \& Sugiarti, 2017).

Pelaksanaan pemberian informasi pada pasien bedah section caesarea di RS PKU Muhammadiyah Gamping Yogyakarta, dilakukan sebebelum pasien melakukan operasi. Dokter menjelaskan kepada pasien atau keluarga pasien mengenai tindakan yang akan diberikan mulai dari diagnosis, tujuan, risiko sampai dengan alternatif tindakan yang akan dilakukan. Persetujuan dilakukan dari pasien mulai mendaftar rawat inap baik melalui IGD atau poliklinik, setelah selesai penjelasan dan menandatangani formulir informed consent pasien akan dibawa ke kamar operasi untuk dilakukan tindakan. 
Berdasarkan Peraturan Menteri Kesehatan RI nomor 129 tahun 2008 tentang standar pelayanan minimal untuk kelengkapan pengisian informed consent yaitu $100 \%$. Kelengkapan pengisian sangat penting karena jika suatu saat tindakan medis yang dilakukan menimbulkan kerugian bagi pasien dan menyebabkan fasilitas pelayanan kesehatan atau rumah sakit menghadapi tuntutan pidana dan perdata (Kementerian Kesehatan RI, 2008).

\section{Simpulan dan Saran}

Pelaksanaan pemberian informasi informed consent di RS PKU Muhammadiyah Gamping Yogyakarta sudah sesuai dengan regulasi yang berlaku yaitu dilaksanakan sebelum melakukan tindakan medis atau operasi, dimana pemberian informasi informed consent dilaksanakan mulai dari pendaftaran rawat inap, IGD, dan poli klinik ketika dokter menghendaki untuk dilakukan tindakan jika darurat. Dalam pelaksanaan pengisian informed consent masih ditemukan cukup banyak formulir informed consent yang tidak terisi lengkap terutama pada bagian autentifikasi penerima informasi atau pasien dikarenakan sebagian besar pasien atau keluarga pasien kurang memahami pentingnya informed consent.

Kelengkapan pengisian formulir informed consent pasien bedah section caesarea di RS PKU Muhammadiyah Gamping Yogyakarta didapatkan hasil bahwa sebagian formulir tidak terisi lengkap dari bulan Mei- Agustus 2020 yaitu sebanyak $28(49,13 \%)$ dari 57 formulir informed consent.

Saran dari penelitian ini adalah sebaiknya RS PKU Muhammadiyah Gamping Yogyakarta perlu melakukan sosialisasi ulang kepada dokter dan professional pemberi asuhan kesehatan terkait pentingnya kelengkapan pengisian formulir informed consent dan dampak yang ditimbulkan dari ketidaklengkapan pengisian informed consent yang menyangkut urusan hukum, sehingga tidak terjadi pengulangan kembali dan para tenaga kesehatan lebih displin lagi dalam kelengkapan pengisian informed consent serta perlu diadakanya pembuatan pedoman pengisian informed consent dalam bentuk poster formulir informed consent yang telah diisi petugas sebagai contoh pengisian formulir informed consent yang benar.

\section{Ucapan Terima Kasih}

Terima kasih disampaikan kepada seluruh pihak yang turut serta membantu terlaksananya penelitian ini.

\section{Daftar Pustaka}

Busro, A. (2018). Aspek Hukum Persetujuan Tindakan Medis (Inform Consent) Dalam pelayanan Kesehatan. Law, Development and Justice Review. https://doi.org/10.14710/ldjr.v1i1.35 70

Hallock, J. L., Rios, R., \& Handa, V. L. (2017). Patient satisfaction and informed consent for surgery. American Journal of Obstetrics and Gynecology.

https://doi.org/10.1016/j.ajog.2017.0 3.020

Jati, S., Sriatmi, A., \& Fikriya, K. (2016). Analisis Persetujuan Tindakan Kedokteran (Informed Consent) Dalam Rangka Persiapan Akreditasirumah Sakitdi Instalasi Bedah Sentral Rsud Kota Semarang. Jurnal Kesehatan Masyarakat (e-Journal).

Kementrian Kesehatan RI. (2008). Menteri Kesehatan Republik Indonesia Nomor: $\quad$ 129/Menkes/SK/II/2008 Tentang Standar Pelayanan Minimal Rumah Sakit Menteri Kesehatan Republik IndonesiA. In Nomor Tambahan Lembaran Negara Nomor 4355 Nomor Tambahan Lembaran Negara Nomor 4400. 
Mavroudis, C., \& Thomas Cook, J. (2020). Informed consent. In Bioethical Controversies in Pediatric Cardiology and Cardiac Surgery. https://doi.org/10.1007/978-3-030-35 660-6_3

Octaria, H., \& Trisna, W. V. (2016). Pelaksanaan Pemberian Informasi dan Kelengkapan Informed Consent di Rumah Sakit Umum Daerah Bangkinang (RSUD Bangkinang). Jurnal Kesehatan Komunitas. https://doi.org/10.25311/jkk.vol3.iss 2.103

Presiden RI. (2009). Undang - Undang RI Nomor 44 Tahun 2009 Tentang Rumah Sakit. Rumah Sakit.

Prihyanto. (2012). Pengaruh Pemberian Informed Consent Terhadap Kecemasan Pre Operasi Sectio Caesarea Dengan Anestesi Spinal di Rsud Raa Soewondo Pati. Tesis.

Sprumont, D. (2017). Informed consent: Do not be afraid. Journal of the Formosan Medical Association. https://doi.org/10.1016/j.jfma.2015.0 8.013

Susilo, A. P., Dalen, J. Van, Scherpbier, A., Tanto, S., Yuhanti, P., \& Ekawati, N. (2013). Nurses' roles in informed consent in a hierarchical and communal context. Nursing Ethics. https://doi.org/10.1177/09697330124 68467

Ulfa, H. M. (2018). Analisa Kelengkapan Informed Consent Tindakan Operasi di Rumah Sakit Sansani Pekanbaru. Indonesian of Health Information Management

Wahyuni, N., \& Sugiarti, I. (2017). Implementasi Pengisian Formulir Informed Consent Kasus Bedah Umum Sebagai Salah Satu Bukti Transaksi Terapeutik Di Rsud Dr. Soekardjo Kota Tasikmalaya Tahun 2017. Jurnal Manajemen Informasi Kesehatan Indonesia (JMIKI).
Wulandari, M., Wasono, H. A., Lestari, S. M. P., \& Maitsya, A. N. (2019). Analisiskelengkapan Pengisian Informed Consent Tindakan Beedah Di Rumah Sakit Pertamina Bintang Amin Tahun 2018. Jurnal Ilmu Kedokteran Dan Kesehatan. https://doi.org/10.33024/jikk.v6i2.22 96 